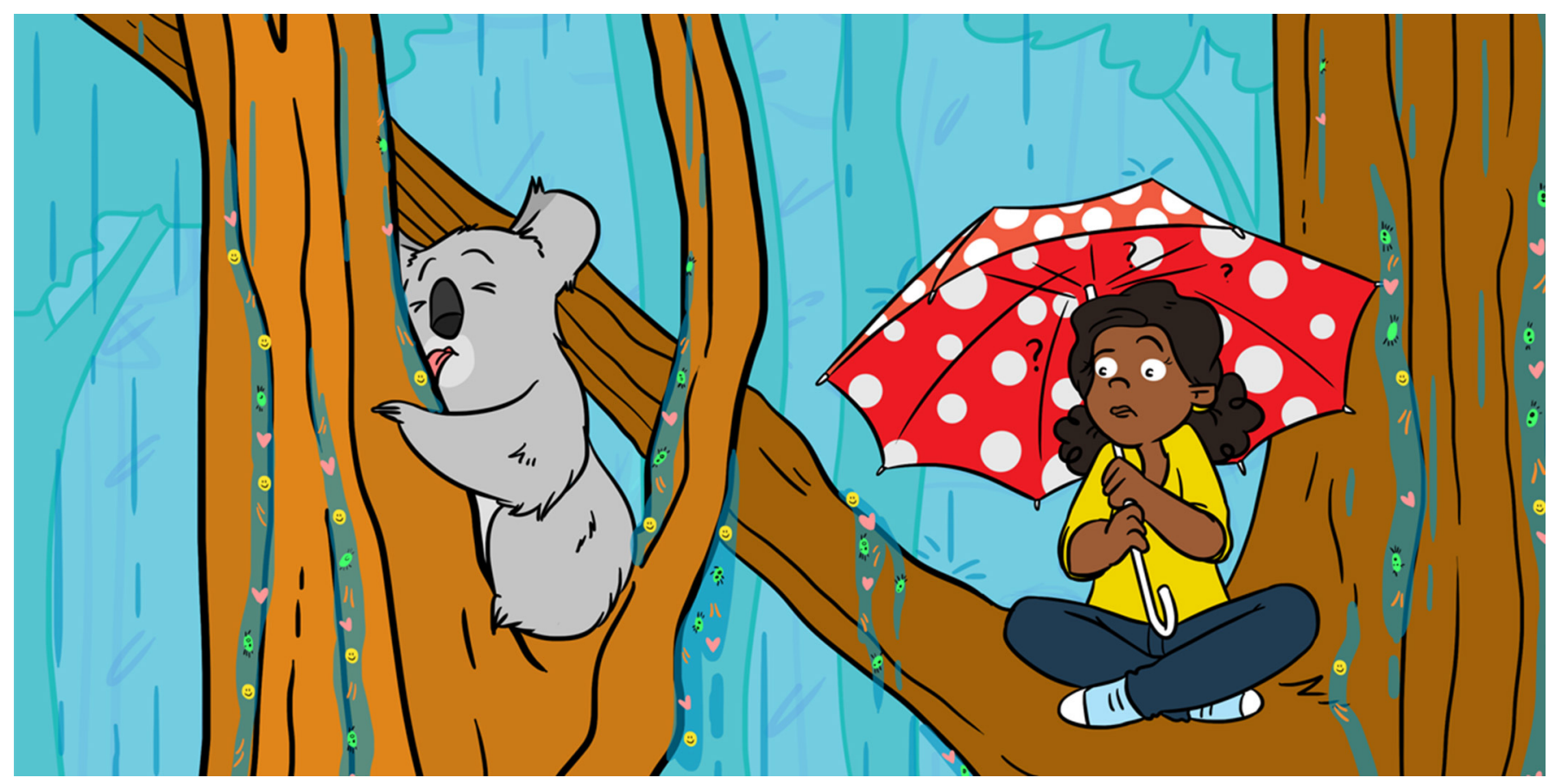

\title{
KOALAS GIVE TREE BARK A LICKING
}

\section{Valentina S. A. Mella ${ }^{1^{*}}$ and John T. Van Stan $I^{2,3^{*}}$}

${ }^{1}$ School of Life and Environmental Sciences, The University of Sydney, Sydney, NSW, Australia

${ }^{2}$ Applied Coastal Research Laboratory, Georgia Southern University, Savannah, GA, United States

${ }^{3}$ Department of Geology \& Geography, Georgia Southern University, Savannah, GA, United States

YOUNG REVIEWER:

JASON

AGE: 9
All animals need water to live, but not all of them need to drink it from their surroundings. Drinking free water from rivers or puddles is just one of many ways that animals get the water they need. Until recently, koalas were thought to get most of their water from the leaves that they eat. But, after years of koala watchers getting caught in the rain, the scientists and volunteers began sharing similar, strange stories. These sleepy animals were waking up during storms and giving the tree bark a lively licking! Surprisingly, koalas appear to drink a type of free water rarely studied: stemflow. This is rainwater that drains down tree bark, and it is not just water. Stemflow picks up all types of things from the bark as it drains, from nutrients and pollutants to bacteria and fungi, raising many new questions for koala scientists.

\section{INTRODUCING THE KOALA'S DIET}

If Mother Nature opened a koala café in the trees of Eastern Australia, the menu would be very simple: leaves. Because of this leafy diet, 
FOLIVORE

An animal that only eats leaves-like a koala.

\section{FREE WATER}

Water that is naturally sitting in, or flowing through, an area, such as water from a river, lake, creek or rainwater in a puddle.

\section{SYSTEMATIC}

Doing something in a planned way, so it can be repeated accurately. koalas are called folivores. Any appetizers on this folivore menu, you ask? None. What about a drink menu? Probably not-especially if the weather has been nice (and rainy). Well, what kind of leaves would be on the menu? Mostly eucalyptus leaves. This menu would certainly not appeal to many other animals on Earth, and not just because of its simplicity. First off, eucalyptus leaves are toxic to most other animals! The eucalyptus trees fill their leaves with toxins to prevent animals from biting them-leaves are the tree's lungs after all. Koalas do not get sick from these leaves because they have evolved special gut bacteria that can detoxify the toxins found in the leaves, so those toxins are digested and expelled quickly. Second, eucalyptus leaves have very little nutritional value. As a result, it is believed that koalas literally eat themselves sick. They stuff their bellies with as many leaves as they can, usually around $500 \mathrm{~g}$ each day-that is three burgers worth!

Finally, most other animals would need at least a glass of water to wash down this toxic meal. But koalas rarely need a glass of water from Mother Nature. Scientists who study animal behavior call the water that is naturally sitting in or flowing through an area free water, and they originally thought that koalas did not need much. While eucalyptus leaves are toxic and not very nutritious, they do store a decent amount of water. Koalas also lose less water than other animals through their skin, through their mouths when they breathe, and even when they pee! Because of this, eucalyptus leaves can meet all the koala's water needs...or, so we thought. It turns out that koalas may drink free water, just not from the usual places like puddles, ponds or rivers. They prefer to wait in their trees until a storm turns the trunk into a tap.

\section{HOW DO SCIENTISTS WATCH KOALA BEHAVIOR?}

We must be careful, consistent, and persistent in studying the ways wild animals interact with other animals and their environments. To do this, scientists prefer to watch wild animals in a systematic, or carefully planned, way. This is because we want other scientists who are not there watching with us to be able to see the same behavior, by doing the same things we did. Thus, in Eastern Australia, scientists plan systematic visits to the koala cafés. The scientists do not order anything, since the food is toxic anyway. Instead, they sit outside the cafés and watch the koalas eat or do whatever the koalas want to do (mostly sleep!). The scientists also do not take a seat in the café. Rather, they sit $10 \mathrm{~m}$ outside with binoculars. Like private eyes, they write down koala behaviors as they happen. Sometimes scientists systematically plan to watch the koalas a bit closer and for longer times, such as overnight. To do this, they set up cameras in the koalas' favorite trees.

Sometimes these systematic visits to the koala café get interrupted by something that was not planned. Storms are a common interruption, and they can be dangerous. Storms can bring lightning, unsafe winds, or just curtains of rain that can block or blur the scientists' view. The 
Figure 1

Koalas

drinking stemflow in their natural habitat. Photos provided by Echidna Walkabout and Koala Clancy Foundation

\section{STEMFLOW}

Rainwater that is collected by a tree canopy and drained down the bark of the trunk. A type of free water.

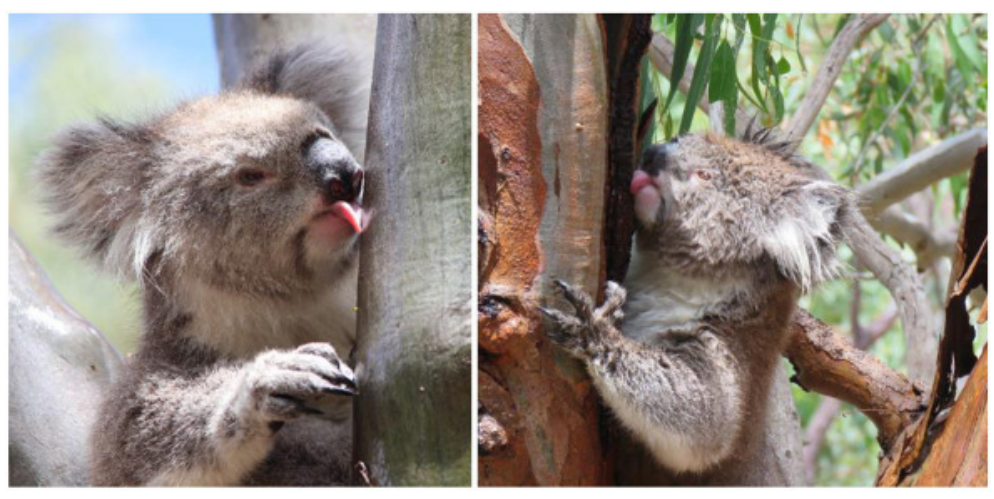

Figure 1

water can also damage the expensive science gear. Most of the time when it rains, koala scientists pack up their gear and plan to come back another time. But some koala scientists and volunteers refused to let rain completely ruin their plans-they kept watching. The watchers who withstood the storm were rewarded with a rainy view of an odd koala behavior.

\section{WHAT DO KOALAS DO WHEN IT RAINS?}

During and after the storm, wet scientists with ruined plans saw koalas drinking free water in trees! The free water was reaching the koalas in an unusual way: by draining down the bark of tree trunks. A portion of the rainwater that hit the leaves and branches was caught by the tree and then drained down the bark, as what is called stemflow. Stemflow can flow down tree trunks for hours. The branches of the koala café acted like waiters, delivering a drink of water right to the koalas at the trunk. Koalas did not just lick the bark for a quick taste. They lapped up stemflow for long periods of time, from 15 to $30 \mathrm{~min}$. One observation counted the number of licks per second, and for these slow animals, two licks every second is a real frenzy of activity. After 34 min straight of steady stemflow sipping, the koala that was being watched took a 2-min break to catch its breath, then began again! Every time that a wet scientist was watching the koala café in the rain, the koalas were drinking this free water. This was a lot of observations (46) over a long period of time (from 2006 to 2019) from different parts of Australia! The number of observations across koala communities over more than a decade suggest that this drinking behavior is a natural behavior of koalas, not just an occasional odd occurrence (Figure 1).

Many important aspects of koala drinking behavior remain unseen. Sure, videos and photographs are great for documenting that this behavior occurs. To see a koala giving tree bark a licking, check out the video below.

Video 1. A koala giving tree bark a licking. Video credit: George Madani and Lachlan Hall. 


\section{Figure 2}

Not all stemflow is the same. The darker the stemflow, the more ingredients are typically dissolved and suspended within it. These substances come from within the tree bark but also from the surrounding environment, like pollutants generated by car exhausts, and might be helpful, such as nutrients, or harmful, such as

disease-causing bacteria and viruses. Photo credits: top left-Forest and Kim Starr from

Wikicommons Media; top middle, right-Emilian Robert Vicol from Pixabay; bottom-Julie

Schooling.

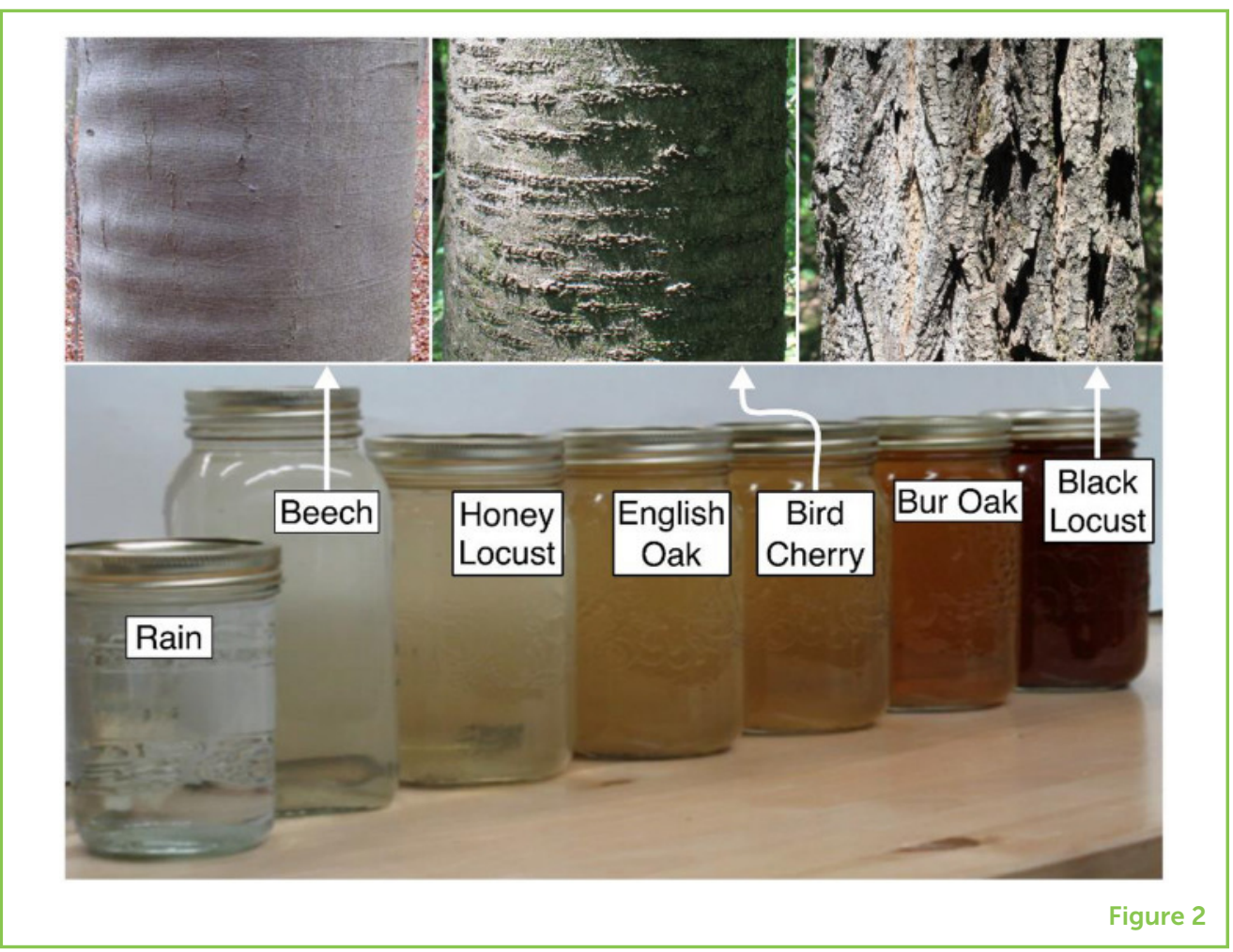

However, standard videos do not provide answers to many important questions. For example, how effective are these animals' tongues at lapping up this thin layer of water streaming down tree bark? To answer questions like this, special high-speed video cameras must be used to catch every little detail of the koala's tongue as it licks. Careful experiments may also be done to calculate the exact amount of stemflow that koala tongues can lap up with a single lick!

\section{WHY DOES IT MATTER THAT KOALAS DRINK FREE WATER?}

Free water is never just water. Water that is flowing and pooling around the environment picks up stuff that could be healthy or cause disease. Although the free water that koalas are drinking comes from rain, its path down the tree branches and trunk adds a few ingredients from the tree bark to the water. In fact, stemflow may contain more ingredients than other types of free water in the natural environment-even more than river and lake water! Stemflow picks up all types of things from the bark as it drains, from nutrients and pollutants to bacteria and fungi. Scientists know very little about stemflow. We do not know much about the bacteria and fungi in stemflow or the potential viruses it might contain. To complicate matters more, different types of trees, and even different trees of the same species, can make different flavors of stemflow (Figure 2). So, do koalas choose to drink cleaner, clearer stemflow? Or do they prefer a murkier, tea-like stemflow? Can the ingredients that the bark gives stemflow be healthy or harmful 
to the koalas? Finally, could trees with high-quality and/or abundant stemflow play some part in koalas' territoriality?

Our research, and all these unanswered questions, are important because the successful conservation of koalas, or any other animal, depends on our understanding of their behavior. Behaviors related to where, how, when, and what kind of water a species drinks can be crucial to that species' survival and if we observe carefully, animals can really tell us what they need. For koalas, continuing this research may help ensure that human activities do not turn off, or taint, the taps flowing down the trunks of their canopy cafés.

\section{ORIGINAL SOURCE ARTICLE}

Mella, V. S. A., Orr, C., Hall, L., Velasco, S., and Madani, G. 2020. An insight into natural koala drinking behaviour. Ethology 126:858-63. doi: 10.1111/eth.13032

SUBMITTED: 23 July 2020; ACCEPTED: 12 May 2021; PUBLISHED ONLINE: 04 June 2021.

EDITED BY: Didone Frigerio, University of Vienna, Austria

CITATION: Mella VSA and Van Stan JT II (2021) Koalas Give Tree Bark a Licking. Front. Young Minds 9:575280. doi: 10.3389/frym.2021.575280

CONFLICT OF INTEREST: The authors declare that the research was conducted in the absence of any commercial or financial relationships that could be construed as a potential conflict of interest.

COPYRIGHT @ 2021 Mella and Van Stan. This is an open-access article distributed under the terms of the Creative Commons Attribution License (CC BY). The use, distribution or reproduction in other forums is permitted, provided the original author(s) and the copyright owner(s) are credited and that the original publication in this journal is cited, in accordance with accepted academic practice. No use, distribution or reproduction is permitted which does not comply with these terms.

\section{YOUNG REVIEWER}

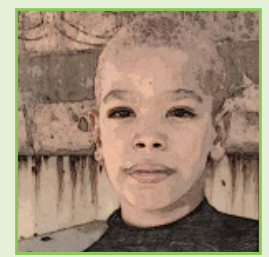

\section{JASON, AGE: 9}

Jason is fascinated by animals and the many ways that humans rely on other animals. He loves having a pet snake whose behaviors he can watch up close. He also enjoys the challenge of searching for and finding wild animals in their natural habitats (including fishing!). 


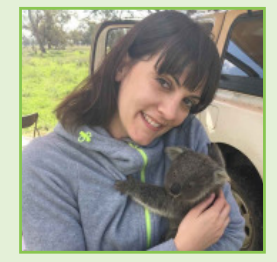

\section{AUTHORS}

\section{VALENTINA S. A. MELLA}

Valentina Mella is a zoologist interested in wildlife ecology, animal behavior, fauna management, and conservation. She currently leads a project investigating the how water availability in the environment affects koala behavior and health. The study plays a pivotal role in the conservation of koala populations, providing practical management solutions to help wild koalas through climate change-driven heatwaves and droughts. *valentina.mella@sydney.edu.au

\section{JOHN T. VAN STAN II}

John Van Stan is an ecohydrologist interested in what happens when plants and water meet during storms-rain, snow, sleet, or otherwise. He currently directs the Applied Coastal Research Laboratory in Savannah, Georgia, USA, leading projects on how wet plants affect coastal soils, shorelines, and society. * professor.vanstanagmail.com. 